\title{
DEVELOPMENT OF SILK FIBROIN AS A BIOMATERIAL FOR WOUND HEALING
}

\author{
SHIVANGI VIG ${ }^{1} \&$ Dr. AMITA WALIA ${ }^{2}$ \\ ${ }^{1}$ Guest Faculty, Department of Fabric and Apparel science, Institute of Home Economics, DU, Delhi, India \\ ${ }^{2}$ Assistant Professor, Department of Fabric and Apparel science, Institute of Home Economics, DU, Delhi, India
}

\begin{abstract}
The Medical textiles sector of technical textiles was one of the fastest developing industries. Today, many special fibres both natural and synthetic including alginate, chitosan, super absorbent fibres, polylactic acid fibres etc. are used as composition for medical textiles. Most of these fibres have properties such as antiseptic, antimicrobial, anti-inflammatory, astringent, ability to accelerate collagen formation and potential for drug delivery which help in early wound healing and hygiene maintenance. For a wound to heal in time, it is essential for the active components of a wound dressing to reach the wound area. In this study, a less explored material i.e. Silk Fibroin was used to prepare a drug delivery matrix by making a solution with Calcium-alcohol.
\end{abstract}

KEYWORDS: Medical textiles, Technical textiles, Collagen formation, Silk Fibroin \& Drug delivery matrix

Received: Mar 20, 2020; Accepted: Apr 10, 2020; Published: May 14, 2020; Paper Id.: IJTFTJUN20203

\section{INTRODUCTION}

Wound is an inescapable event in life. If not managed properly, the wound may become contaminated and infected therefore wound management is a critical process. There are a number of wound types and this variety in wound kinds have leads in a variety of wound dressings with fresh products that are launched frequently to aim at targeting distinct features of wound healing procedure. Direct delivery of these wound healing representatives to the wound site is beneficial in order to heal a wound. Hydrocolloids, alginate, hydrogels, polyurethane, collagen, chitosan, pectin along with hyaluronic acid were some of the polymers used for the drug delivery to all types of wound.

The Medical textiles sector of technical textiles was among the fastest developing industries. It was one of the growing fields within specialized textiles as well as the employ of textile substances for medical, as well as healthcare goods varieties from basic gauge or bandage to scaffolds for tissue culturing and huge diversity of permanent body implants. Textile goods were ubiquitous in an area of human hygiene and medical exercise. Today, many special fibres both natural and synthetic including alginate, chitosan, super absorbent fibres, polylactic acid fibres etc. are used as composition for medical textiles. Most of these fibres have properties such as antiseptic, antimicrobial, anti-inflammatory, astringent, ability to accelerate collagen formation and potential for drug delivery which help in early wound healing and hygiene maintenance.

Silk was employed as a biomedical substance over a period. Fibrous proteins, like silks as well as collagens, were featured by a very routinely initial series, which results in crucial uniformity in subordinate composition, i.e., triple helices in the case of collagens and b-sheets in case of variety of the silks (Figure 1). This kind of proteins normally display significant technical attributes, in difference to the catalytic as well as molecular identification purposes of globular proteins. Due to these impressive technical attributes, this relation of proteins gives a significant set of substance alternatives in areas of restrained drug release, biomaterials and scaffolds for tissue engineering [1]. 
Silk Fibroin, as every fibrous protein was insoluble from water because of high concentration of hydrophobic amino acids. Therefore, it is essential to convert Fibroin into dispersion so that it can be used as a biomaterial. A variety of gels, membranes or powders could acquire from Silk fibroin solution. Silk fibroin membranes are widely used as biomaterials, for instance, they are used as wound dressing, drug delivery system or contact lenses. For a wound to heal in time, it is essential for the active components of a wound dressing to reach the wound area to come in action, therefore it is important to have a drug delivery matrix included in the wound dressing which seeps out the active extracts. Many natural elements such as chitosan, proteins like silk fibroin are used as a drug delivery matrix in wound dressing. Silk fibroin is a less explored but effective natural component used for the purpose.
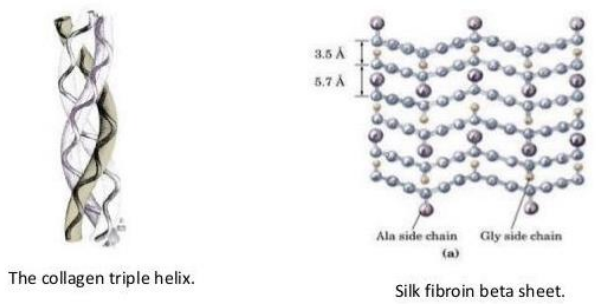

Figure 1: Fibrous Protein Structures.

Source: https://www.google.com/search?client=safari\&rls=en \&biw=1199\&bih=862\&tbm=isch\&sa=1\&ei=BZk8XLfCon7vgTgy6HgAQ\&q=triple+helix+and+beta+sheet+structure+of+protein\&oq=triple+helix+and+beta+sheet+structure+o f+protein\&gs_l=img.3...88546.102385..102847...0.0..0.442.13061.2-38j9j1 .....0....1..gws-wizimg.......0i67j0j0i8i30j0i24.3cpG-6wCC_Y\#imgrc=7YSBqgLavOzTGM

\section{METHODOLOGY}

B.mori cocoons were sourced through Central Silk Technological Research Institute (Bangalore, India). The method employed for preparation of silk fibroin based biomaterial was taken from Zhang, H., et.al [2]. Cocoons from B.mori are degummed through incubating in a composites of sodium dodecyl sulphate (SDS; $0.25 \%$, w/v) and sodium carbonate $(0.25 \%$, w/v) in $98^{\circ} \mathrm{C}$ for $30 \mathrm{mins}$. These samples are then cooled to room temperature, cleaned three times in purified water, and dried at $65^{\circ} \mathrm{C}$ overnight[1]. The proportion of cocoons and formula were 1:100(w/v). The degummed silk fibres have secluded with other silk protein, sericin. This secluded fibroin fibres are individually dispersed in concentrated $\mathrm{CaCl}_{2} \mathrm{Solution}$ combined among ethanol and water $(1: 2: 8 \mathrm{~mol})$ at $65^{\circ} \mathrm{C}$ in a water bath for 4 hours. The proportion of the silk fibres along with solution is $1: 20(\mathrm{~m} / \mathrm{v})$. To prepare this solution, $110.98 \mathrm{~g}$ of anhydrous calcium chloride (desiccated at $105^{\circ} \mathrm{C}$ in a drying oven for several hours) were dispersed within a liquid solvent comprising of $92.14 \mathrm{~g}(2 \mathrm{moles}, 116.78 \mathrm{ml})$ ethanol and $144 \mathrm{ml}$ demineralised water. The calcium chloride was dissolved in the dissolvent at $20^{\circ} \mathrm{C}$ until complete dissolution of the salt crystals. To $190 \mathrm{ml}$ of this solution $10 \mathrm{~g}$ of silk fibroin (cut into small pieces) was added. The aqueous result of silk fibroin have acquired through dialyzing in opposition of moving water. Following that, the causing dialyzed solution was poured in sterilized falcons covered with parafilm with 5-6 holes. The samples were then deep freezed at $-80^{\circ} \mathrm{C}$ for 1 hour and then were lyophilized for 48 hours in a pre-set lypholizer at $-80^{\circ} \mathrm{C}$. Dry silk powder was obtained after lypholization. The dry powder was stocked at $4^{\circ} \mathrm{C}$ till utilize.

The silk fibroins treated using $\mathrm{CaCl}_{2}$-ethanol solution were plated on a slide and were seen under electronic microscope for analyzing longitudinal morphology of silk fibroin. 


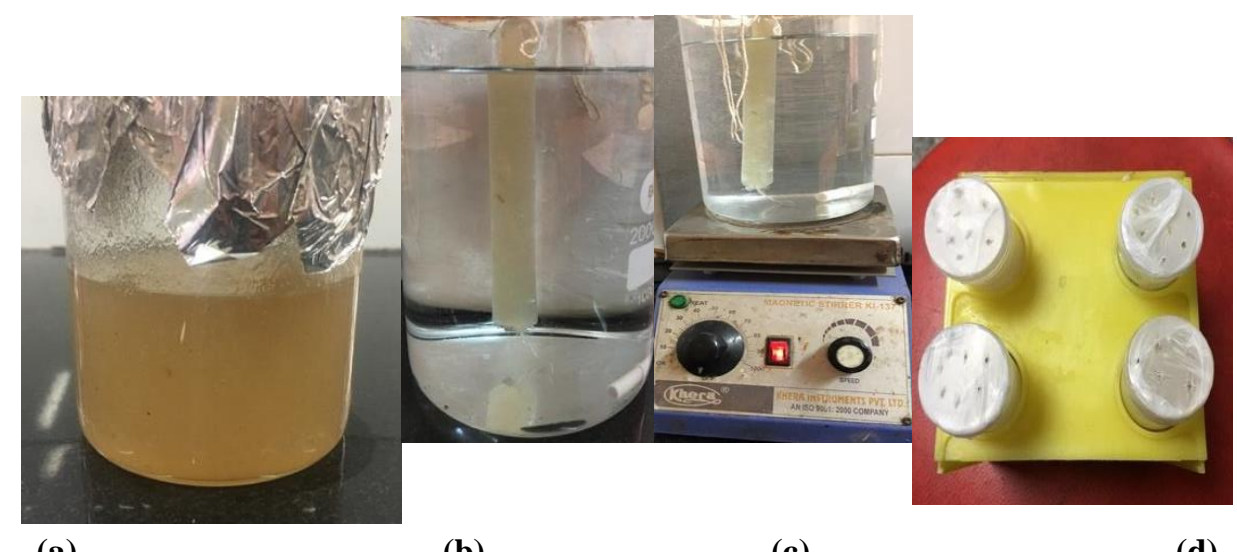

(a)

(b)

(c)

(d)

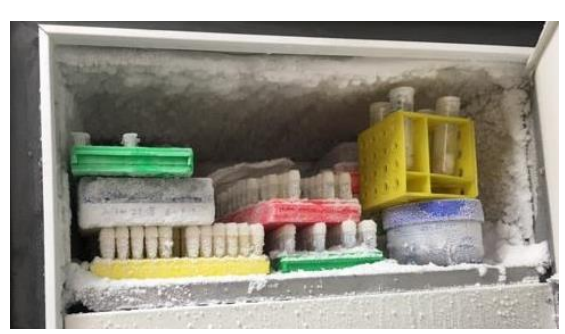

(e)

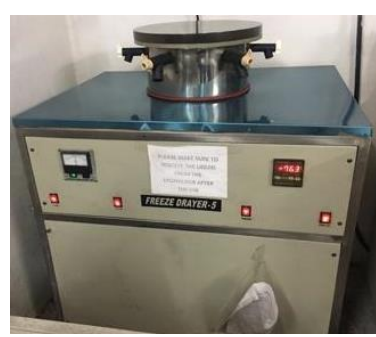

(f)

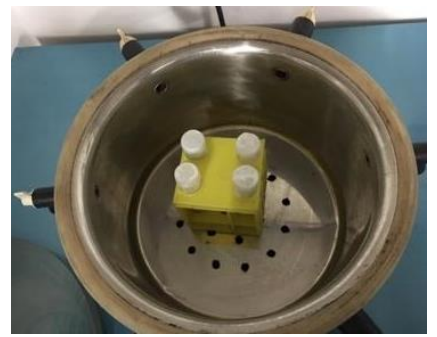

(g)

(b)Dialysis bag in double distilled water

(c)Dialysis on magnetic stirrer

(d)Preparation for Lypholization

(e)Deep freezer

(f)and (g) : Lypholizer

Figure 2: Preparation and Lypholization of Silk Fibroin.

\section{RESULTS AND DISCUSSIONS}

Revived silk fibroin was demonstrated as an appealing applicant of a conveyor for drug or therapeutic proteins supply. To form a drug delivery, matrix degummed Bombyx Mori cocoons were opened by hand and silk fibres have been sliced into little samples. 1:2:8 molar solutions of calcium chloride, ethanol as well as water were prepared, to which 10g of silk fibroin cut pieces were dissolved. This calcium chloride, ethanol, water and silk fibroin solution turned to a viscous brownish solution after being maintained in a water bath for 4 hours in $65^{\circ} \mathrm{C}$.

That above viscous solution was dialyzed in a dialysis bag dipped in double distilled water on a magnetic stirrer overnight with 3-4 water changes. White coloured silk fibroin solution was obtained after dialysis, which was freezed in a deep freezer at $-80^{\circ} \mathrm{C}$ for one hour followed by lypholization for 48 hours at $-80^{\circ} \mathrm{C}$. White coloured powder (Figure 3 ) obtained on lypholysis was stored in a refrigerator in $4^{\circ} \mathrm{C}$ till utilize. 


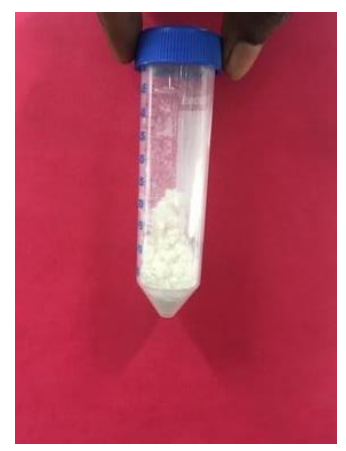

\section{Figure 3: Regenerated Silk Fibroin Powder Treated with $\mathrm{CaCl}_{2}$-ethanol.}

The silk fibroins treated with $\mathrm{CaCl}_{2}$-ethanol after lyphlozation, along with degummed silk fibroins were seen under electronic microscope to observe the morphology (Figure 4). The dimension and formation of the degummed silk fibroins are usual, spherical tubes. In difference, the revived silk fibroins are asymmetrical shaped. This might have evolved from the integrator of little micelles that happened in the aqueous solutions of $\mathrm{CaCl}_{2}$-ethanol.

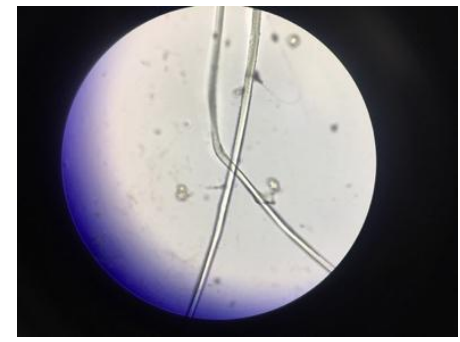

(a)

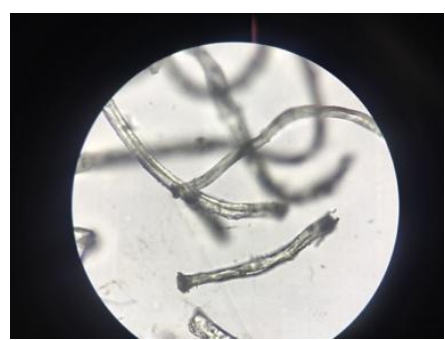

(b)
(a) Degummed silk fibroin
(b) regenerated silk fibroin treated with $\mathrm{CaCl}_{2}$-ethanol

Figure 4: Morphology of Silk Fibroins as seen by Electronic Microscope.

\section{CONCLUSIONS}

- Being non-toxic, non-immunogenic, and biocompatible with a wide span of animal species have permitted for the supporter attributes of silk fibroin as well as silk-like proteins to be utilized for biomedical motives.

- $\quad$ Regenerated silk fibroin is an attractive candidate for drug delivery matrix.

\section{ACKNOWLEDGEMENTS}

Authors are grateful to the Department of Fabric and Apparel Science, Department of Biochemistry, Institute of Home Economics, University of Delhi for providing assistance to carry out this research work.

\section{REFERENCES}

1. Altman, G., Diaz, F., Jakuba, C., Calabro, T., Horan, R., Chen, J., Lu, H., Richmond.J., Kalpan, D., (2002), Silk based biomaterials, Journal of Biomaterials, 401-416.

2. Zhang, H., Li, L., Dai, F., Zhang, H., Ni, B., Zhou, W., Yang, X., Wu, Y., (2012), Preparation and characterization of silk fibroin 
as a biomaterial with potential for drug delivery, Journal of translation medicine, vol.10:117.

3. Chudasama, Dinesh. "Protection against electromagnetic radiation with textile material." Int. J. Electr. Electron. Eng. Res 3 (2013): 293-302.

4. CHUDASAMA, DINESH. "Wearable electronics." International Journal of Electrical and Electronics Engineering Research (IJEEER) 4.5 (2014): 27-32.

5. Sharma, Ravikant, B. A. B. I. T. A. Chaudhary, and U. S. H. A. Sayed. "Value Addition Finishing Of Protein Fibres Used For Technical Textile." International Journal Of Medicine And Pharmaceutical Sciences, 7 (3), 3136 (2017).

6. Fernando, E. A. S. K. "Mathematical model for warp tension with various back rest settings and relationship with technological parameters." International Journal of General Engineering and Technology (IJGET) 3.2 (2014): 17-26.

7. Gangawane, Prashant, and Usha Sayed. "Innovative Use of outdated Doxycycline Hydrochloride to Dye wool." International Journal of Medicine and Pharmaceutical Sciences 2014; 4 (2): 4346 (2014).

8. CHUDASAMA, DINESH. "Wearable electronics." International Journal of Electrical and Electronics Engineering Research (IJEEER) 4.5 (2014): 27-32. 

